\title{
DISTRIBUIÇÃO DE EQUIPAMENTOS PÚBLICOS DE LAZER PARA ANÁLISE DA QUALIDADE DE VIDA URBANA: PROPOSTA METODOLÓGICA E APLICAÇÃO À CIDADE DE MONTES CLAROS-MG
}

\author{
${ }^{1}$ Isabela Veloso Lopes Versiani
}

\begin{abstract}
Resumo
Objetivo do estudo: apresentar a metodologia empregada e aplicação de indicadores adaptados de Sistemas de Indicadores de Qualidade de vida Urbana ao campo do lazer, com análise a partir da distribuição de equipamentos públicos de lazer em uma cidade média, no caso Montes Claros-MG.
\end{abstract}

Metodologia/abordagem: natureza descritiva, com base no levantamento de dados quantitativos por meio da aplicação de um conjunto de indicadores para analisar a relação do lazer com a qualidade de vida urbana, complementada por visitas de campo e produção de mapas temáticos georreferenciados.

Originalidade/Relevância: embora o lazer seja reafirmado nos instrumentos da Política Urbana no Brasil como um direito social essencial à melhoria da qualidade de vida, sua efetivação ainda encontra-se distante. Ao aproximar essa discussão dos recentes Sistemas de Indicadores de Qualidade de Vida Urbana, evidenciase o potencial dessa compreensão e aplicação para ações de planejamento e políticas públicas específicas.

Principais resultados: foram identificadas carências e disparidades entre as regiões de renda mais baixa e alta da cidade, principalmente no que se refere à distribuição, fator de diversidade e estado de conservação dos equipamentos.

Contribuições teóricas/metodológicas: a pesquisa aproxima a discussão da relação do lazer com a qualidade de vida urbana ao campo empírico, ainda escasso de estudos mais específicos.

Contribuições sociais / para a gestão: ressalta-se o potencial desse tipo de levantamento no direcionamento de ações mais efetivas para democratização do lazer e melhoria da qualidade de vida urbana, colaborando para o aprimoramento constante de indicadores e novas possibilidades de estudos.

Palavras-chave: Lazer. Qualidade de Vida Urbana. Equipamentos Públicos.

${ }^{1}$ Universidade Estadual de Montes Claros - Unimontes, Minas Gerais, (Brasil). E-mail: isabelamoc @ yahoo.com.br
Orcid id: http://orcid.org/0000-0001-7966-187X 


\title{
DISTRIBUTION OF PUBLIC LEISURE EQUIPMENT TO ANALYZE URBAN QUALITY OF LIFE: METHODOLOGICAL PROPOSAL AND APPLICATION TO THE CITY OF MONTES CLAROS-MG
}

\begin{abstract}
Objective of the study: to present the methodology used and the application of indicators adapted from Urban Quality of Life Indicators Systems to the leisure field, with analysis from the distribution of public leisure equipment in a medium-sized city, in the case of Montes Claros-MG.
\end{abstract}

Methodology / approach: descriptive, based on the survey of quantitative data through the application of a set of indicators to analyze the relationship between leisure and urban quality of life, complemented by field visits and the production of georeferenced thematic maps.

Originality / Relevance: although leisure is reaffirmed in the instruments of Urban Policy in Brazil as an essential right to improve quality of life, its realization is still distant. By bringing this discussion closer to the recent Urban Quality of Life Indicators Systems, the potential of this understanding and application for planning actions and specific public policies is highlighted.

Main results: deficiencies and disparities were identified between the lower and upper income regions of the city, especially regarding the distribution, diversity factor and the state of conservation of the equipment.

Theoretical / methodological contributions: the research conducted brings the discussion of the relationship between leisure and the quality of urban life to the empirical field, still scarce of more specific studies.

Social / management contributions: emphasize the potential of this type of survey in the direction of more effective actions for democratization of leisure and improvement of urban quality of life, contributing to the constant improvement of indicators and new study possibilities.

Keywords: Leisure. Urban Quality of Life. Public Equipment. 


\section{DISTRIBUCIÓN DE EQUIPOS PÚBLICOS DE OCIO PARA EL ANÁLISIS DE LA CALIDAD DE VIDA URBANA: PROPUESTA METODOLÓGICA Y APLICACIÓN A LA CIUDAD DE MONTES CLAROS - MG}

\section{Resumen}

Objetivo del estudio: presentar la metodología empleada y la aplicación de indicadores adaptados de los Sistemas de Indicadores de la Calidad de Vida Urbana al campo del ocio, con análisis de la distribución de equipos públicos de ocio en una ciudad mediana, en el caso de Montes Claros-MG.

Metodología / enfoque: descriptivo, basado en la encuesta de datos cuantitativos mediante la aplicación de un conjunto de indicadores para analizar la relación entre el ocio y la calidad de vida urbana, complementado con visitas de campo y la producción de mapas temáticos georreferenciados.

Originalidad / Relevancia: aunque el ocio se reafirma en los instrumentos de Política Urbana en Brasil como un derecho esencial para mejorar la calidad de vida, su realización aún es distante. Al acercar esta discusión a los recientes Sistemas de Indicadores de Calidad de Vida Urbana, se destaca el potencial de esta comprensión y aplicación para acciones de planificación y políticas públicas específicas.

Resultados principales: se identificaron deficiencias y disparidades entre las regiones de ingresos bajos y altos de la ciudad, especialmente en la distribución, el factor de diversidad y el estado de conservación del equipo.

Contribuciones teóricas / metodológicas: la investigación realizada lleva la discusión de la relación entre el ocio y la calidad de la vida urbana al campo empírico, aún escaso de estudios más específicos.

Contribuciones sociales / de gestión: se enfatiza el potencial de este tipo de encuesta en la dirección de acciones más efectivas para la democratización del ocio y la mejora de la calidad de vida urbana, contribuyendo a la mejora constante de los indicadores y nuevas posibilidades de estúdios.

Palabras clave: Ocio. Calidad de Vida Urbana. Equipo Publico. 


\section{INTRODUÇÃO}

Os desafios para que o lazer seja, de fato, reconhecido como um direito social e tenha sua vivência democratizada nas cidades são grandes, especialmente quando se analisa sua relação com a lógica de produção capitalista do espaço urbano, hegemônica, (Castells, 2006; Lojkine, 1997), contrapondo-se à cidadania e à dimensão política para uma nova produção social do espaço na promoção da vida urbana e na busca pelo direito à cidade (; Damiani, 2009; Lefebvre, 2008).

Diante desse quadro, o uso do solo urbano tem sido marcado pela lógica do capital, o que contribui para a segregação socioespacial e desigualdade na distribuição e acessibilidade aos bens e equipamentos coletivos, mesmo com os recentes instrumentos trazidos pelo Estatuto da Cidade (2001) e seus desdobramentos para regulamentar a Política Urbana no Brasil em busca de um ambiente urbano mais justo e equilibrado.

Embora o lazer tenha sua condição constitucional de direito social assegurada pelo Estatuto da Cidade (2001), ao ser legitimado como um dos mecanismos essenciais de incremento de qualidade de vida ao lado do direito ao uso e ocupação do solo urbano, ao saneamento, à infraestrutura urbana, aos serviços públicos, acesso ao mercado de trabalho, entre outros, ainda existem muitas dificuldades para que, de fato, esses direitos sejam incorporados ao cotidiano da vida urbana.

Tal realidade é vivenciada não só nas grandes metrópoles e cidades brasileiras, como também no contexto crescente das cidades médias, em expansão no Brasil e compreendidas como aquelas entre 100 mil e 500 mil habitantes, como no caso de Montes Claros-MG, única cidade do Norte de Minas Gerais nessa faixa, com população urbana de mais de 344 mil habitantes (IBGE, 2010) e que apresenta um quadro intenso de desigualdades socioespaciais e sobreposição de práticas e espaços de lazer privado cada vez mais presentes.

Efetivar o direito ao lazer na realidade do desenvolvimento urbano é reconhecer, também, a necessidade do espaço público de lazer como um direito a ser assegurado pelo Poder Público Municipal e vivenciado pela população. Nessa discussão, o tema do lazer se insere no âmbito das políticas urbanas, realçando a necessidade de uma política de investimento dirigida para superar a falta de espaços e de políticas públicas para sua ocupação, que se legitima, principalmente, quando o espaço de lazer se caracteriza como "espaço de encontro, convívio, do encontro com o 'novo' e com o diferente, lugar de práticas culturais, de criação, de transformação e de vivências diversas, no que diz respeito a valores, conhecimentos e experiências" (Gomes, 2006, p.73).

Segundo Pellegrin (2004, p.72), diante da pluralidade de conflitos e contrastes evidenciados, há que se ressaltar que:

a lógica do capital se estende também sobre a distribuição dos equipamentos urbanos em geral, inclusive os de lazer $[. .$.$] ; 2) a rede urbana de$ equipamentos de lazer opera estreitamente ligada à dinâmica das outras redes de equipamentos, de transporte, habitação, etc., o que deve ser levado em conta pela Administração Pública ao desenvolver o planejamento urbano.

Ao ser incorporado à discussão do planejamento urbano das cidades, o lazer pode contribuir para um maior desenvolvimento social e bem-estar dos seus habitantes, fazendo-se presente na formulação e na efetivação de políticas públicas voltadas à sua democratização, entendidas como formas de garantir sua vivência na experiência cotidiana dos indivíduos e contribuir com a melhoria da qualidade de vida, expressão cada vez mais recorrente nos debates sobre o presente e futuro das cidades em todo mundo.

A discussão sobre a qualidade de vida urbana tem se fortalecido e ampliado por meio de diferentes sistemas de indicadores para monitoramento. Esses sistemas, em essência, se desenvolvem baseados em metodologias preocupadas com a construção e aplicação de diferentes indicadores para comparar regiões de uma mesma cidade, redes de cidades ou países, com o objetivo de aprimorar técnicas de mensuração e compartilhar experiências no âmbito do planejamento urbano e das políticas públicas que dependem do real conhecimento dos problemas a serem enfrentados para sua eficácia, inclusive na relação com o lazer.

Nesse processo, o levantamento de informações e diagnósticos acerca da realidade intraurbana de muitas cidades brasileiras ao mesmo tempo em que é necessário, diante da complexidade das questões urbanas colocadas que comprometem a qualidade de vida da população, mostra-se como um desafio particular ao seu próprio planejamento, devido à falta de dados sistematizados e padronizados em muitos setores das Administrações Públicas, o que compromete a gestão urbana e o direcionamento de políticas públicas, inclusive, no campo do lazer. 
A presença de questões referentes ao lazer e o compartilhamento de experiências entre esses sistemas são importantes para o aprimoramento de indicadores, contribuindo para sua legitimação no debate em torno da qualidade de vida nas cidades e no direcionamento de ações específicas para suas políticas setoriais articuladas com as políticas urbanas. Entende-se assim, que um dos fatores para mensurar qualidade de vida urbana é a identificação do número de espaços e equipamentos públicos de lazer existentes em uma cidade. Apesar do esforço para construção de indicadores no campo do lazer e esporte, Santos (2009) considera que, no que diz respeito aos equipamentos de lazer, falta na literatura dados mais consistentes sobre como avaliá-los.

Compreender como se dá essa configuração no campo do lazer pode colaborar para ampliar seu debate no meio urbano, evidenciado suas potencialidades na superação de algumas das dificuldades cotidianas de sua democratização. Embora em diversos meios e discussões seja recorrente uma associação entre o lazer e a qualidade de vida, o aprofundamento teórico e, principalmente, empírico dessa relação no meio urbano ainda é escasso.

A partir dessa constatação, o presente artigo relata a metodologia utilizada na proposição de um conjunto de indicadores para o campo do lazer relacionado à Qualidade de Vida Urbana, com base em duas experiências de Sistemas de Monitoramento específicas, e, posterior aplicação dos mesmos à dimensão intraurbana da cidade de Montes Claros-MG para levantamento da distribuição dos equipamentos públicos de lazer existentes e possíveis impactos na análise da qualidade de vida. Espera-se que a pesquisa realizada possa contribuir para o debate como mais uma experiência que visa auxiliar e aprofundar a troca de informações e o desenvolvimento desse campo recente de estudos.

\section{REFERENCIAL TEÓRICO}

O lazer, entendido como um fenômeno social, tem sido diretamente influenciado por aspectos econômicos, políticos, sociais e culturais, com desdobramentos não só para sua compreensão como necessidade humana e manifestação cultural (Gomes, 2014), ou na relação com o trabalho e tempo destinado para suas vivências (Navarro, 2006), mas também em sua dimensão espacial e das diferentes contradições que envolvem seus espaços e equipamentos nas cidades (Versiani et al., 2019).

A ameaça à existência de espaços públicos como praças, quadras esportivas, parques urbanos, entre outros, e concorrência com a "mercadorização" do lazer no ambiente urbano, na qual suas vivências e espaços têm sido cada vez mais privatizados e convertidos em mercadoria, muitas vezes associados aos interesses capitalistas imobiliários, contribuem ainda mais para processos de exclusão e intensificação de desigualdades socioespaciais, uma vez que nem todos têm as mesmas condições e oportunidades de usufruir do lazer da mesma forma (Padilha, 2006; Marcellino, 2006; Gomes, 2006), o que dificulta a sua implementação enquanto um direito social.

Para Pellegrin (2004, p. 72), a discussão dos espaços de lazer e de seus equipamentos na cidade faz parte do desenho da cidade moderna e está em contato direto com forças de ordem econômica e política, na qual saltam aos olhos contrastes urbanos diversos: "áreas nas quais os equipamentos são abundantes, variados e bem conservados e áreas nas quais eles são raros, mal conservados, áreas de fácil acesso e áreas de difícil acesso, equipamentos superlotados e equipamentos subutilizados". Essa oferta desigual de equipamentos públicos compromete diretamente a qualidade de vida de parte significativa da população.

Aprofundar o conhecimento da realidade do lazer nas cidades é fundamental para o seu desenvolvimento enquanto área da qualidade de vida e muitos sistemas de indicadores de qualidade de vida urbana têm procurado inseri-lo como uma das variáveis a serem pesquisadas, levando em consideração, principalmente, a distribuição de equipamentos culturais, de infraestrutura esportiva, de parques, praças e outros, pelas cidades ${ }^{2}$.

A preocupação com a qualidade de vida tem sido recorrente nos mais variados campos. Em função de sua complexidade, diferentes abordagens e problemáticas, evidenciam-se em muitos estudos recentes a busca por uma sistematização teórica e empírica acerca da qualidade de vida, que no meio urbano, tem sua visão apreendida não apenas em uma dimensão individual e subjetiva, mas que contempla, essencialmente, sua dimensão coletiva. Levando-se em conta o grau de adequação das características espaciais, ambientais e sociais da cidade às metas, planos e aspirações dos indivíduos, o que deverá ser priorizado é a ligação da qualidade de vida com o desenvolvimento urbano no sentido de aproximá-la ao cotidiano de seus habitantes, com o objetivo de efetivar suas capacidades e ampliar
2 Dentre as experiências analisadas de forma mais específica em outro trabalho destacam-se: Global City Indicators; The Quality of Life Project - da Nova Zelândia; Sistema de Monitorização da Qualidade de Vida Urbana de Porto; Programa Bogotá Como Vámos; Índice de Qualidade de Vida Urbana - IQVU de Belo Horizonte; e Rede Nossa São Paulo. 
suas possibilidades de escolhas em um ambiente urbano mais justo, humano, cidadão e ambientalmente sustentável (Souza, 2008; Vitte \& Keinert, 2009; Nahas, 2009).

Essa perspectiva recente é destacada por Herculano (1998) pela sua possibilidade em tornar o conceito de qualidade de vida um instrumental sociológico, um novo campo não só de estudos, mas de intervenção, definido pelo estudo substantivo, descritivo e normativo das condições de vida social, econômica e ambiental. O conceito de qualidade de vida é então explicitado como:

[...] a soma das condições econômicas, ambientais, científico-culturais e políticas coletivamente construídas e postas à disposição dos indivíduos para que estes possam realizar suas potencialidades: inclui a acessibilidade à produção e ao consumo, aos meios para produzir cultura, ciência e arte, bem como pressupõe a existência de mecanismos de comunicação, de informação, de participação e de influência nos destinos coletivos, através da gestão territorial que assegure água e ar limpo, higidez ambiental, equipamentos coletivos urbanos, alimentos saudáveis e a disponibilidade de espaços naturais amenos urbanos, bem como a preservação de ecossistemas naturais (Herculano, 1998, p. 17).

Essa discussão tem se fortalecido pela crescente sistematização de indicadores de qualidade de vida urbana articulados por redes de cidades, organizações da sociedade civil, administrações públicas municipais e estudos locais, que buscam aprofundar o conhecimento das necessidades da população e de especificidades socioespaciais, vinculadas não só a aspectos econômicos, mas que envolvem também questões ligadas ao meio ambiente, serviços urbanos, habitação, mobilidade e transporte, educação, participação política, segurança, saúde, lazer, entre outros, contribuindo para um direcionamento mais efetivo de metas e ações no âmbito do planejamento e das políticas públicas, além de servir de base de informações para reivindicações da própria população (Leva, 2005). Na discussão sobre indicadores, Januzzi (2009, p.133) expõe que indicador social é:

uma medida em geral quantitativa dotada de significado social substantivo, usado para substituir, quantificar ou operacionalizar um conceito social abstrato, de interesse teórico (para a pesquisa acadêmica) ou programático (para formulação de políticas). É um recurso metodológico, empiricamente referido, que informa algo sobre um aspecto da realidade social ou sobre mudanças que estão se processando na mesma. Os indicadores sociais se prestam a subsidiar as atividades de planejamento público e formulação de políticas sociais nas diferentes esferas de governo, possibilitam o monitoramento das condições de vida e bem-estar da população por parte do poder público e sociedade civil e permitem o aprofundamento da investigação acadêmica sobre a mudança social e sobre os determinantes dos diferentes fenômenos sociais.

Nesse tipo de produção do conhecimento, há o cruzamento de informações entre o Poder Público, a sociedade civil e a própria população, garantido por um processo de gestão democrática e transparente, o que amplia o acesso à informação como um dos pilares para o exercício da cidadania e implantação de um modelo de gestão administrativa que privilegie o conhecimento da realidade social para propostas de intervenção, com utilização de diferentes plataformas e ferramentas.

$\mathrm{Na}$ relação com as cidades, o geoprocessamento tem sido cada vez mais utilizado como ferramenta para subsidiar ações de planejamento urbano. Como campo crescente de estudos no âmbito urbano brasileiro, sua utilização permite investigar e conhecer melhor diversos fatores que impactam a qualidade de vida urbana, dentre eles questões relacionadas à distribuição de equipamentos e serviços públicos, desigualdades socioespaciais e problemas ambientais, que podem auxiliar o Poder Público no direcionamento de políticas urbanas integradas a outras políticas públicas para redução de problemas e contradições na configuração espacial das cidades.

Dentre as diversas técnicas de geoprocessamento existentes, destacam-se tecnologias e métodos para o processamento digital de dados e informações geográficas, geralmente associados à constituição de Sistemas de Informação Geográfica (SIG), que permitem realizar análises complexas ao integrar dados de diversas fontes e criar bancos de dados georreferenciados (Leite, 2006; Câmara; Davis, 2001), importantes para aprofundar o conhecimento do espaço intraurbano.

No processo de construção de indicadores, deve-se dar atenção especial à definição de unidades espaciais de cálculo para o dimensionamento das disparidades no interior dessas cidades. Segundo Nahas (2009, p.126), a construção de indicadores georreferenciados em unidades espaciais intraurbanas previamente definidas é fundamental para compreender os diferentes e desordenados processos de ocupação do solo nas cidades, que produziram um mosaico espacial profundamente desigual em múltiplos aspectos e setores, cuja compreensão "é fundamento indispensável ao planejamento municipal voltado para a formulação de políticas públicas que promovam a redução de tais desigualdades".

A aplicação de indicadores para dimensionar qualidade de vida urbana constitui um campo recente de estudos, que pode se transformar em uma importante fonte de informação acerca da realidade urbana e 
contribuir para o entendimento da informação enquanto direito, o que amplia o diálogo entre a gestão pública, a sociedade civil e a própria população.

Ao expor as desigualdades intraurbanas, em alguns casos, o levantamento desses indicadores torna-se uma ferramenta valiosa para o direcionamento de políticas públicas específicas e para ações integradas de planejamento urbano, uma vez que possibilitam "a identificação de prioridades espaciais para certos investimentos, especialmente localização de equipamentos sociais que promovam um acesso equitativo a serviços e bens, promovendo a inclusão e a equidade" (Nahas, 2008, p.96), fundamentais em um contexto tão desigual de acesso às vivências de lazer nas cidades.

\section{METODOLOGIA}

O estudo se caracteriza por sua natureza descritiva com base no levantamento de dados quantitativos, além de utilizar análise documental, consulta a outras fontes e visitas de campo para tecer as principais considerações acerca das informações coletadas na cidade de Montes Claros-MG, que foram georreferenciadas com base na proposta de regionalização de Leite (2006), o que permite trabalhar os dados localizados a partir de unidades espaciais específicas.

Essa proposta padroniza as duas divisões intraurbanas presentes no Município (a divisão em loteamentos da Prefeitura e a divisão em setores censitários, utilizada pelo IBGE - para a realização do censo demográfico), o que possibilita correlacionar informações demográficas e socioeconômicas a partir da reconstrução do mapa urbano de Montes Claros, sobrepondo setores censitários e loteamentos com base no conhecimento empírico e nos dados do IBGE, e resulta em uma regionalização urbana da cidade coerente com a semelhança socioeconômica e a localização geográfica (Leite, 2006).

Por ser o lazer um tema bastante amplo, que envolve diversos interesses culturais - dentre eles físicos, artísticos, manuais, intelectuais, sociais (Dumazedier, 1980); entre outras classificações - nessa pesquisa foi dada ênfase à estrutura do espaço público de lazer urbano destinada aos interesses físico-esportivos, na perspectiva de que tais atividades possuem uma estreita relação com as políticas públicas de esporte/lazer que vem sendo desenvolvidas e com o uso dos espaços públicos disponíveis em maior número nas cidades brasileiras.

Assim, foram considerados como espaços públicos de lazer os equipamentos específicos levantados junto à seção de Unidades de Esporte e Lazer, da Secretaria Municipal de Juventude, Esporte e Lazer (SEJEL) Prefeitura Municipal de Montes Claros (PMMC), e os identificados na pesquisa de campo realizada
(Dez./2010), como ginásios (2), quadras esportivas (38), campos de futebol em áreas institucionais (14) e áreas verdes (3), playgrounds (9), pistas de skate (2), pistas de caminhada (3) e conjunto de barras de ginástica (10), no total de 81 equipamentos.

A partir da regionalização intraurbana proposta, os equipamentos públicos de lazer levantados foram georreferenciados utilizando-se tecnologias associadas ao Sistema de Informação Geográfica (SIG), que possibilita a aquisição, armazenamento, análise e apresentação dos dados na superfície terrestre. Esses dados foram processados no Software ArcGIS 9.3, com utilização da Imagem de Satélite Quick Bird (2005). Para conferência dos dados levantados, foi também utilizada a Imagem de Satélite disponibilizada pelo Google Earth.

A análise da relação do lazer com a qualidade de vida urbana na cidade de Montes Claros, a partir da aplicação de indicadores específicos na área, foi influenciada por duas experiências de Sistemas de Indicadores expressivos no contexto nacional, em parte pela metodologia utilizada pelo Observatório Cidadão da Rede Nossa São Paulo, referente ao indicador elaborado para os Equipamentos Esportivos, e pela metodologia de cálculo utilizada pelo Índice de Qualidade de Vida Urbana, da Prefeitura de Belo Horizonte (IQVU - BH), para variável Esporte.

A influência da metodologia utilizada pelo Observatório Cidadão aplicada à cidade de Montes Claros resultou no cálculo do indicador referente ao fator de desigualdade regiões, inclusive para as que apresentaram indicador igual a zero, entendendo-se que se ela possui zero equipamento, seu fator de desigualdade é exatamente igual à proporção da região com melhor classificação. Assim, quanto maior é o fator, maior será a desigualdade entre as regiões.

Além desses indicadores, também foi calculado o fator de diversidade de equipamentos para cada região de planejamento. Esse indicador foi construído com base na atribuição de valor igual a 1 para cada categoria de equipamento presente na região de planejamento, com exceção das quadras esportivas, em que esse valor de 1 foi desmembrado para cada tipo de quadra, por exemplo: quadra poliesportiva (1); quadra poliesportiva coberta (1); quadra de peteca (1) e quadra de futebol de areia (1), perfazendo um total de diversidade de equipamentos na cidade, somadas as outras categorias de equipamentos, que varia de 0 a 10 .

A metodologia utilizada para a variável Esporte do IQVU-BH permite conhecer o índice referente ao número de espaços públicos para recreação existentes por 1.000 habitantes em cada uma das 81 Unidades de Planejamento (UP) de Belo Horizonte. O cálculo é realizado a partir da relação entre Quadras, Campos $e$ Pistas de Cooper por 1.000 [(número de quadras, 
campos e pistas/ população) x 1.000], apresentado por meio do Mapa Temático IQVU - Esportes.

Aplicado à cidade de Montes Claros, a adequação metodológica teve como resultado a produção do Índice de Qualidade de Vida para o Lazer (IQV Lazer), que permite conhecer o índice referente ao número de equipamentos públicos de lazer existentes por 1.000 habitantes em cada região de planejamento. Esse índice é calculado de forma semelhante à utilizada pelo IQVU$\mathrm{BH}$, partindo-se da relação entre o número de equipamentos públicos pré-definidos (quadras, ginásios, campos, barras de ginástica, pistas de caminhada, skate e playgrounds) por 1.000 habitantes [(número de equipamentos/população da região) x 1.000].

A apresentação da sistematização dos dados e análise dos indicadores levantados foi realizada a partir da produção de mapas correlacionados a variáveis como renda e distribuição populacional, a serem expostos nos resultados. Além da apresentação dos dados objetivos, procedeu-se a uma análise qualitativa dos equipamentos georreferenciados com base na visita de campo e registro imagético desses equipamentos, o que permitiu tecer considerações específicas acerca do seu estado de conservação e de sua infraestrutura, e alguns apontamentos mais amplos sobre seus usuários e formas de apropriação, a serem apresentados na sequência.

\section{RESULTADOS}

\section{Caracterização das Regiões de Planejamento em Montes Claros-MG e Mapas Temáticos}

A caracterização da dimensão intraurbana da cidade de Montes Claros é marcada por um processo de ocupação do solo urbano fragmentado e heterogêneo, com uma divisão socioeconômica em áreas com maior ou menor grau de infraestrutura. Variáveis como nível de renda e distribuição populacional retratam a tendência à periferização das classes de renda mais baixa, sobretudo no Norte (Santos Reis, Distrito Industrial, Village do Lago), Leste (Independência) e Sul (Santo Inácio), e regiões de renda baixa (Alto da Boa Vista, Maracanã, Delfino, Carmelo, Renascença, Vila Oliveira, Major Prates, Lourdes e Sumaré), também acompanhadas por uma maior densidade populacional, o que configura na cidade a predominância majoritária de uma população menos favorecida, que ocupa regiões com carências de infraestrutura urbana, sobretudo nas áreas mais periféricas, onde o valor do solo urbano é mais baixo. Tais características ficam evidentes na exposição das figuras 1 e 2 lado a lado.

\section{Figura 1: Mapa de Distribuição por Renda Figura 2: Mapa de Distribuição Populacional}

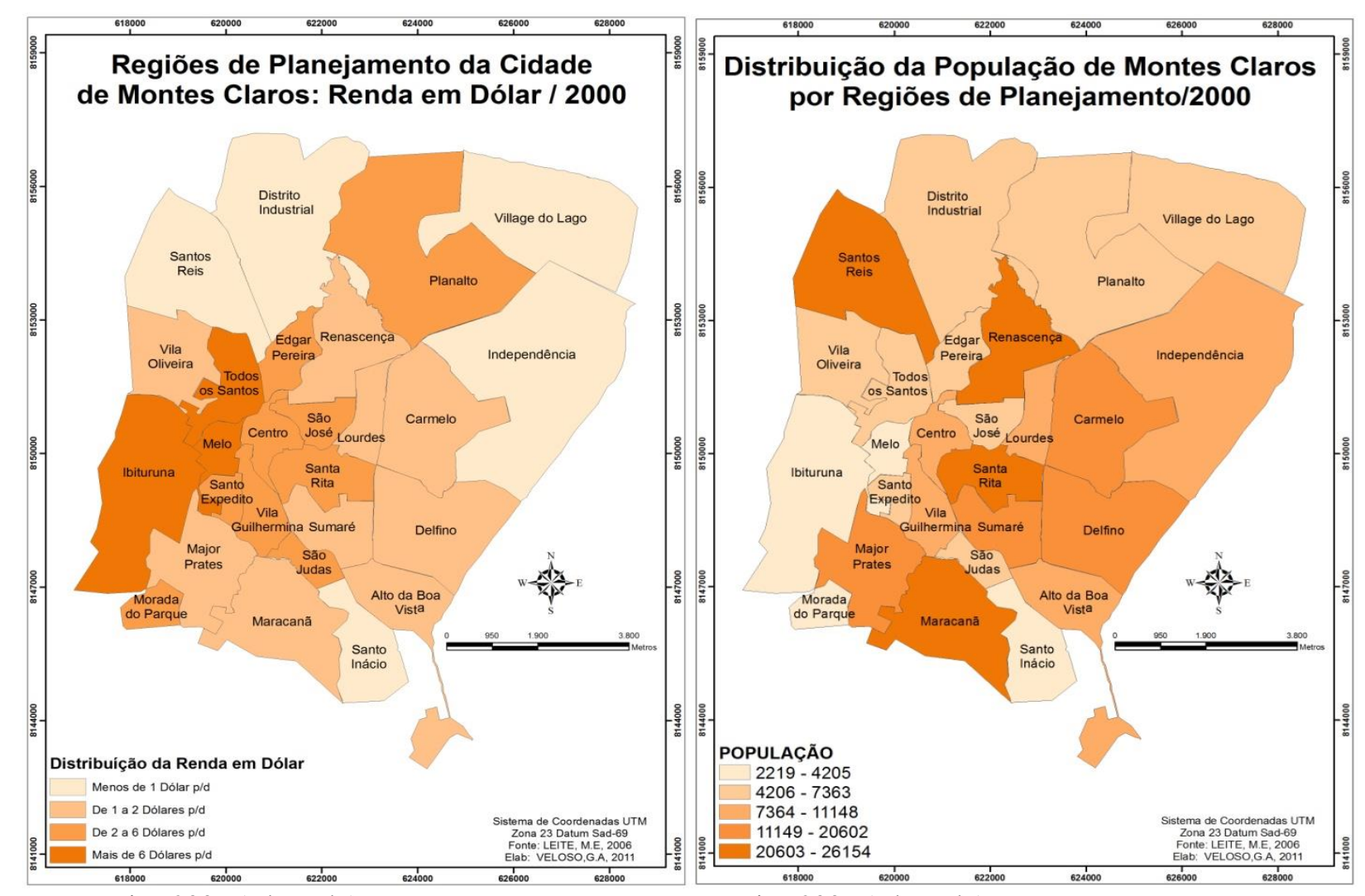

Fonte: Leite, 2006 (adaptado).

Fonte: Leite, 2006 (adaptado). 
Quanto mais a região se aproxima da área central, verifica-se um aumento da renda, tendendo para regiões de renda média (São Judas, Santa Rita, Planalto, Edgar Pereira, Vila Guilhermina, Santo Expedito) e média alta (São José, Morada do Parque e Centro). Os contrastes se acentuam na periferia Sudoeste da cidade, onde se localizam as regiões com população de maior poder aquisitivo e pouca densidade populacional, com casas de alto padrão e concentração de condomínios fechados luxuosos (Ibituruna, Melo, Todos os Santos). Essa configuração socioespacial irá ter desdobramentos diretos na distribuição dos equipamentos, conforme evidenciado na distribuição dos equipamentos a partir dos Mapas Temáticos.

\section{Quadras e Ginásios}

Além de serem os equipamentos mais numerosos (33), as quadras poliesportivas dos bairros também são os equipamentos mais bem distribuídos na cidade, conforme retrata o mapa da figura 4. Mesmo assim, verifica-se que essa distribuição é insuficiente para atender às demandas de algumas regiões e registra-se uma carência nas regiões periféricas. Uma importante fonte de dados para confirmar essa constatação foi a consulta popular do Orçamento Participativo (OP), realizada em 2007, pela Prefeitura Municipal de Montes Claros (PMMC). No caso das quadras, percebe-se que das 42 demandas do OP organizadas pela Secretaria Adjunta de Esporte e Lazer na época, 19 bairros solicitaram reformas ou melhoramentos de quadras poliesportivas.

Esse tipo de demanda foi comprovado na pesquisa de campo (2010), quando se verificou condições precárias de uso em quadras de várias regiões, sendo que as mesmas foram classificadas para a análise de sua infraestrutura a partir de três conceitos: Ruim sendo as quadras que possuem, em geral, uma situação precária do piso, falta de equipamentos esportivos, alambrados e pintura geral; Razoável sendo as quadras que, na maioria, apesar de possuírem equipamentos esportivos, os mesmos encontram-se deteriorados, assim como os alambrados, quando existentes, e piso com danificações; Boa, quando as quadras possuem praticamente todos os requisitos em bom estado e iluminação própria ou da praça. Abaixo, a Figura 4 exemplifica cada um desses conceitos, respectivamente.

\section{Figura 3: Exemplos de Classificação da infraestrutura das quadras}

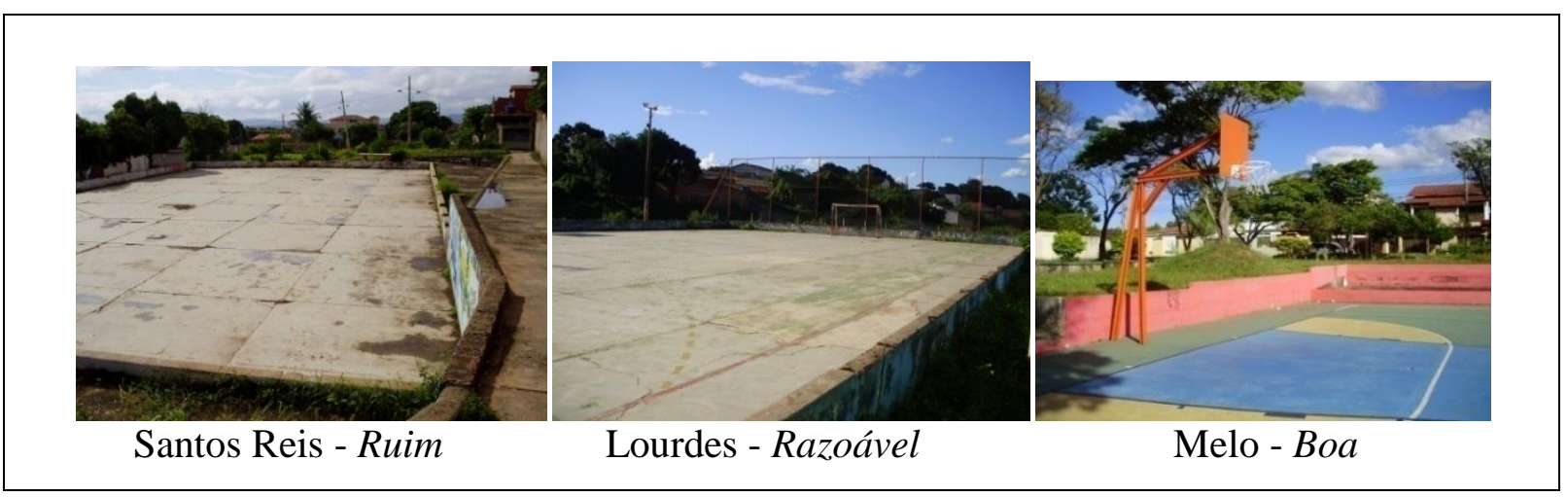

Fonte: Arquivo da autora.

Essa classificação também está apresentada na legenda ao lado do Mapa da figura 4, que contempla a localização das quadras esportivas e ginásios distribuídos nas 26 Regiões de Planejamento. Percebe-se que seis, das nove quadras com classificação de infraestrutura ruim, estão localizadas em bairros de renda baixa ou muito baixa, tendência semelhante à classificação das quadras com infraestrutura razoável. Das quinze quadras com essa classificação, apenas duas estão localizadas em bairros de renda média. Assim, das 24 quadras classificadas como ruim ou razoável, 19 , quase $80 \%$, estão localizadas em área de renda baixa ou muito baixa. Por outro lado, verifica-se que seis, das nove quadras poliesportivas com infraestrutura boa, estão localizadas em bairros de renda média e alta. 
Figura 4: Mapa de Distribuição das Quadras e Ginásios

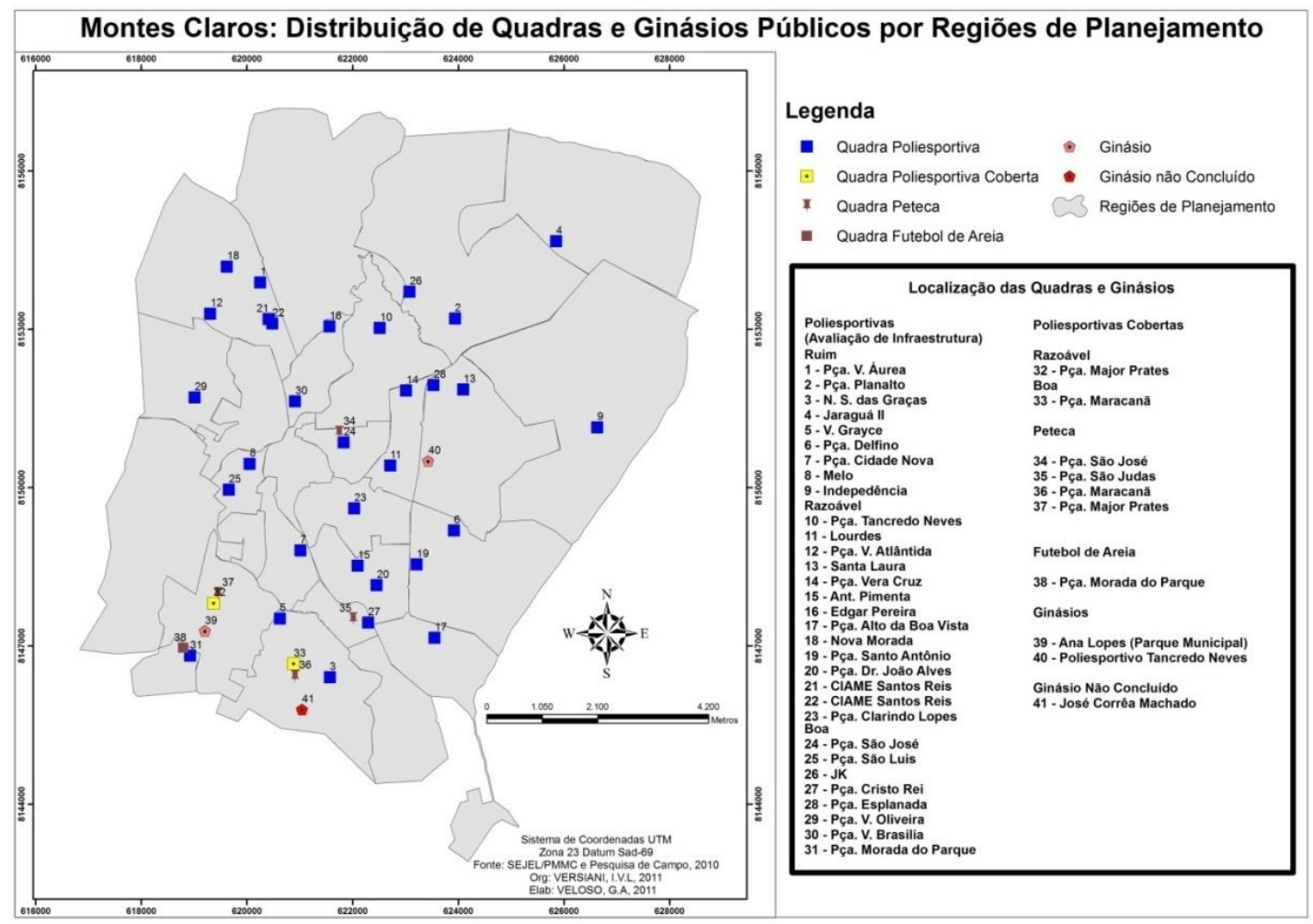

Fonte: Arquivo do autor.

A análise da infraestrutura e conservação evidenciam que a qualidade das quadras é superior em quase todas as regiões de melhor renda. $\mathrm{O}$ mesmo fato ocorre, de maneira mais marcante ainda, quando se analisa a situação dos playgrounds. Outro aspecto importante a ser enfatizado é a existência de apenas duas quadras poliesportivas cobertas e dois ginásios. A cobertura das quadras ou existência de ginásios possibilita uma ampliação de seu uso, tanto devido à proteção do sol ou da chuva durante a prática esportiva/recreativa, como também de realização de outras atividades pela própria comunidade, potencializando seu uso pela população. $\mathrm{O}$ mesmo fato ocorre com as quadras que possuem iluminação da praça ou iluminação própria, pois se amplia sua utilização no horário noturno, além de aumentar a sensação de segurança da população no local.

\section{Campos de Futebol de Várzea}

Com relação aos campos de futebol de várzea, podese considerar que essa é uma categoria de equipamento de lazer que corre sério risco de extinção nas grandes e médias cidades brasileiras, por ser diretamente afetada pelo crescimento urbano acelerado, expansão da malha urbana, invasões, especulação imobiliária e aprovação de novos loteamentos a qualquer tempo. Antes distantes, hoje em número reduzido, o campo de "várzea" praticamente não se encontra mais na várzea, ele está dentro da cidade, próximo das casas, cercado por ruas, avenidas e interesses divergentes.

De um lado, as crianças, jovens e adultos que fazem do campo local de encontro, convívio, brincadeira, esporte, enfim, de lazer. Do outro, agentes imobiliários a serviço da especulação capitalista para a construção de novas casas, novos prédios, novos empreendimentos. Em meio à disputa de interesses inerentes ao crescimento da cidade, o jogo "fora de campo" não tem sido favorável à preservação do significado histórico, afetivo e/ou simbólico dessas áreas, muitas vezes corroborado pelo próprio Poder Público Municipal, que nos locais onde funcionavam os campos aprovam loteamentos ou projetos sem nenhum questionamento ou, pior, compactuam com trocas de áreas institucionais agora "valorizadas" por outras mais distantes para atender a interesses específicos, que não são os interesses coletivos.

Os campos de futebol da cidade de Montes Claros também "sobrevivem" com dificuldades em meio ao crescimento urbano e à especulação imobiliária. Tal é a complexidade que cerca a existência e permanência dessas áreas como campos de futebol, que foi grande a dificuldade para proceder à classificação da área em que estavam localizados, além de informado que no período 
II de 2005 a 2010, 11 campos, aproximadamente, deixaram de existir. Foram identificados 14 campos em área institucional e 03 em área verde, além de 16 campos em área particular ou indefinida.

Apesar de os campos em área particular serem apropriados para uso coletivo da população do seu entorno, a velocidade com que a ocupação dos vazios urbanos tem ocorrido em algumas regiões indica que esses campos serão loteados em breve. Porém, como forma de registrar o problema iminente em muitas regiões, eles também foram identificados na figura 5 , que contempla o Mapa sobre esse tipo de equipamento. Além dos campos em área particular, os campos inseridos em área ainda "não loteada" ou indefinida não foram contabilizados.

$\mathrm{Na}$ distribuição dos campos de futebol no mapa da figura 5, percebe-se que a maior concentração está em regiões que ainda possuem grandes vazios urbanos, à espera de valorização dos terrenos e instalação de infraestrutura para serem loteados. Nas regiões mais valorizadas, como áreas próximas do centro, de ocupação mais antiga, ou na "periferia" sudoeste, há alguns lotes vagos, mas não existem campos de futebol.

De acordo com Mapa elaborado por Leite (2006), a partir de fonte da SEPLAN (PMMC), a maioria dos grandes vazios urbanos está localizada na parte Leste da cidade, nas regiões do Delfino, Carmelo e
Independência. Há também grandes vazios urbanos mais ao nordeste, na região do Village do Lago, e um na região do Planalto. Mais ao Sudeste, há grandes vazios urbanos na região do Santo Inácio e Alto da Boa Vista, o que pode comprometer a existências de campos nessas áreas em um futuro bem próximo. Também, na região do Distrito Industrial, dos cinco campos, apenas o campo do Industrial está em área institucional, o que é preocupante para a população dos bairros que os utilizam.

A segunda região que concentra o maior número de campos de futebol é a do Carmelo, com dois campos em área institucional, além de contar com outros dois campos em área particular e/ou indefinida. Logo em seguida aparece a região do Major Prates, com dois campos em área institucional e um em área particular, e a do Delfino, com um campo em área institucional, um em área verde e outro em área particular. A região do Santo Inácio pode ser considerada uma das mais problemáticas da cidade, pois não há nenhum tipo de equipamento público de lazer, apenas a existência de três campos em área particular, situação semelhante à do Independência, que possui apenas uma quadra poliesportiva e um campo de futebol, com metade dele em área verde e metade em área particular, portanto não contabilizado.

Figura 5: Mapa de Distribuição dos Campos de Futebol

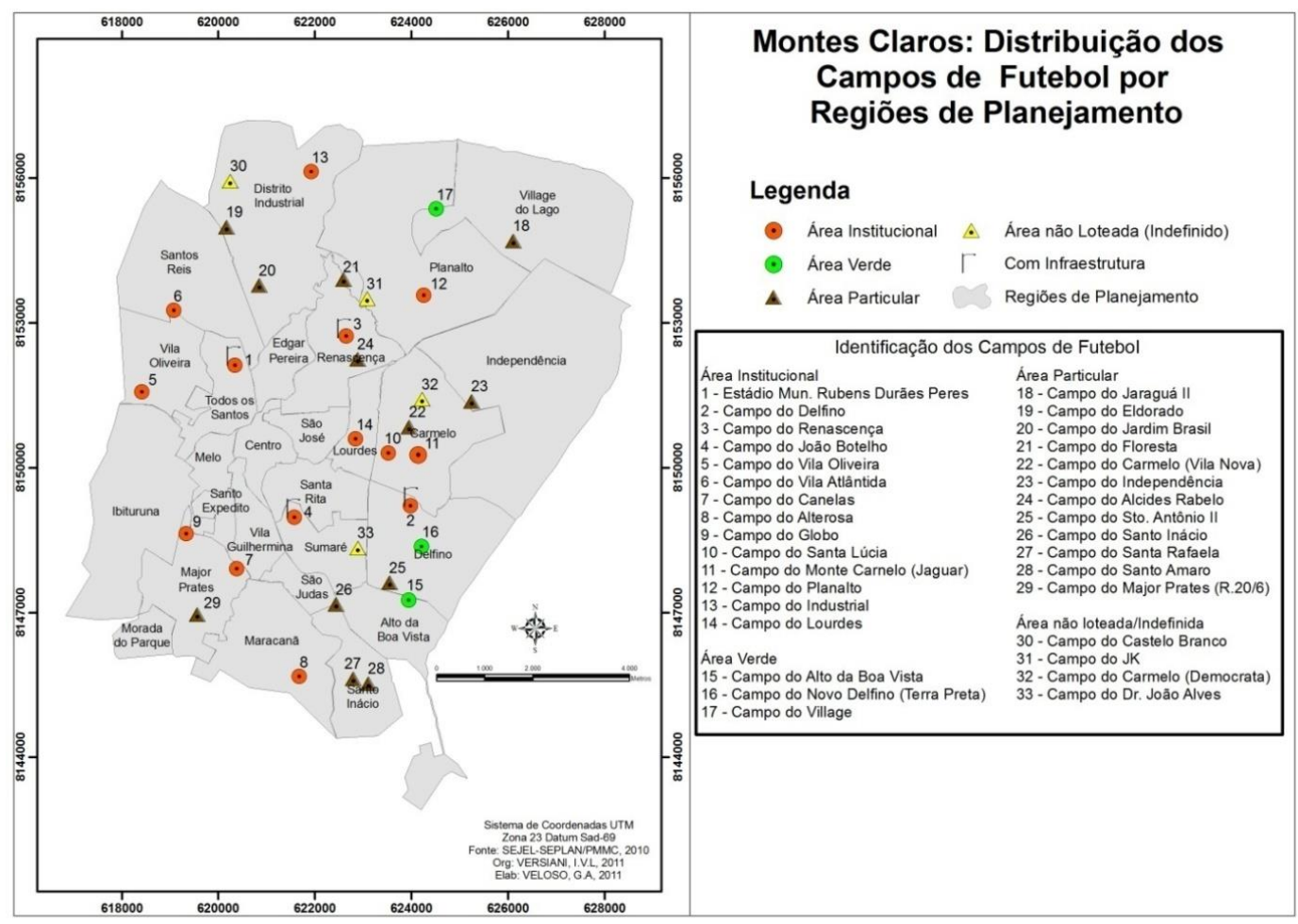

Fonte: Arquivo da autora. 
Nas outras regiões que possuem campos, a existência de pelo menos um em área verde ou institucional é, de certa forma, uma segurança para a população que os utiliza, embora essa situação dependa de uma posição firme do Poder Público Municipal na sua garantia e proteção, o que nem sempre pode acontecer. Porém, os campos de futebol em área verde dependem de autorização da Secretaria Municipal de Meio Ambiente (SEMA) para qualquer medida de manutenção e somente poderão ser considerados campos, de fato, e passar por melhorias efetivas a partir de um processo com base na lei de desafetação.

Já nos campos em área institucional, a intervenção do Poder Público para benfeitorias pode ser mais incisiva. Dos 14 campos nessa classificação, apenas quatro apresentam algum tipo de infraestrutura, o que foi identificado no Mapa da figura 5 por um símbolo específico. Por infraestrutura nos campos entende-se a presença de algum desses aspectos: gramado, iluminação própria, alambrado e/ou vestiários. No caso dos quatro campos, o da região do Todos os Santos é o mais bem estruturado. Chamado de Estádio Municipal Rubens Durães Peres, possui todos esses aspectos, além de arquibancada.

$\mathrm{O}$ número relativamente mais alto de quadras poliesportivas e campos de futebol, e a presença em mais da metade das regiões, favorece uma melhor distribuição desses dois tipos de equipamentos, sobretudo dos campos de futebol evidenciados nas áreas periféricas com grandes vazios urbanos sendo, às vezes, o único equipamento existente. Por outro lado, os outros equipamentos públicos de lazer identificados na pesquisa de campo, por estarem presentes em menor número nas regiões de planejamento, serão os principais indicativos de desigualdades percebidas no levantamento do fator de diversidade de equipamentos.

\section{Outros equipamentos públicos de lazer e locais de caminhada}

Embora a existência de quadras poliesportivas e campos de futebol sejam importantes, principalmente do ponto de vista da população identificado nas demandas do OP, na visita de campo percebeu-se que esses equipamentos são utilizados por públicos bem específicos. Mesmo não tendo sido objeto direto de análise desse trabalho, e por isso, servindo apenas como um apontamento mais amplo, notou-se que o público majoritário que utiliza as quadras nos bairros são crianças mais velhas e jovens do sexo masculino, fenômeno semelhante à utilização dos campos de futebol, também por homens adultos, enquanto que as crianças menores, as meninas, as mulheres e os idosos praticamente não utilizam esses equipamentos de forma espontânea, evidenciando a necessidade de uma maior diversidade de equipamentos e programas para atender a esses públicos nas diferentes regiões, principalmente naquelas de renda mais baixa e baixa, que praticamente não possuem outros tipos de equipamentos.

Um desses equipamentos são os playgrounds públicos, também conhecidos como parquinhos infantis, geralmente formados por conjuntos de brinquedos para serem utilizados por crianças até 12 anos, importantes para o lazer infantil nos bairros. Presente em apenas nove regiões, o que já é um dado alarmante diante de uma população tão numerosa e do grande número de bairros, sete desses equipamentos estão localizados em regiões de renda média e alta. As exceções são dois playgrounds existentes: um localizado na Praça da região da Vila Oliveira e o outro, no Parque Municipal, região do Major Prates.

Além dessa constatação, quando se analisa a infraestrutura e o estado de conservação desses playgrounds, tomando como parâmetro a renda média e o número de habitantes da região em que eles estão localizados, as diferenças são ainda mais consideráveis, principalmente na região do Santa Rita, que embora esteja classificada como região de renda média baixa, é a quarta mais populosa.

Dos nove playgrounds, o da Praça do Clarindo Lopes, na região do Santa Rita, e o da Praça da Vila Oliveira são os que estão em piores condições de uso, além de contar com um número muito reduzido de brinquedos. Já o do Parque Municipal, apesar de ter uma maior diversidade de brinquedos, também apresenta problemas em alguns, podendo ser classificado como em situação razoável.

Os outros cinco playgrounds estão localizados em bairros de renda média e alta. $\mathrm{O}$ estado de conservação desses equipamentos está melhor do que os que foram apresentados. Na Praça do Cristo Rei, região do São Judas, há um playground integrado em madeira, com cerca de quatro brinquedos. $\mathrm{O}$ playground da Praça do Morada do Parque tem cerca de seis brinquedos. Na Praça do Todos os Santos, o playground possui por volta de nove brinquedos. Os destaques são os playgrounds da Praça do São José, que tem cerca de 12 brinquedos, e na Praça da Igreja Rosa Mística, região do Melo, com 20 brinquedos. Por último, o playground do Parque Florestal da Sapucaia é o maior, com brinquedos variados e amplas áreas livres para as crianças. 
Figura 6: Exemplos de Playgrounds infantis nas diferentes Regiões

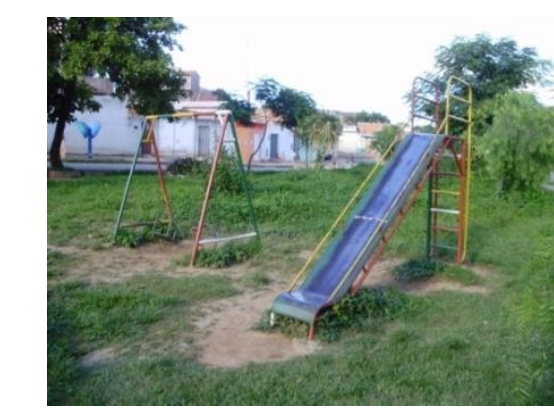

Praça do Clarindo Lopes (Santa Rita)

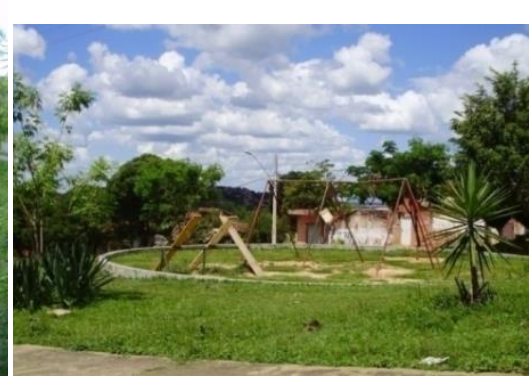

Vila Oliveira

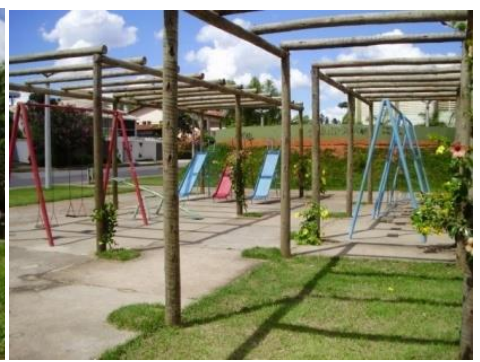

Praça da Igreja Rosa Mística (Melo)

Fonte: Arquivo da autora.

O Mapa da figura 7 evidencia a concentração desse tipo de equipamento na região Centro-Sudoeste da cidade e os registros imagéticos expõem ainda mais a desigualdade quando se verifica que nas três regiões de maior renda da cidade há três playgrounds totalizando cerca de 50 brinquedos. Ao percorrer as regiões na visita de campo, realizada durante período de férias escolares, era grande o número de crianças brincando nas portas das casas e ruas de vários bairros nas regiões mais carentes de infraestrutura e renda.

O espaço doméstico e o espaço da rua podem ser apropriados pela população para diferentes vivências do lazer, embora não se constituam em equipamentos específicos para essas práticas. Além disso, as condições materiais das famílias irão influenciar em um maior ou menor acesso das crianças e jovens a determinadas vivências, especialmente daquelas ligadas ao lazer enquanto consumo - dos equipamentos no "quintal" das próprias residências aos jogos eletrônicos e acesso à internet, da ida ao clube ou do passeio ao Shopping Center para brincar nos centros de diversão, ir ao cinema e/ou lanchar.

Se nem todos têm as mesmas condições para "consumir" o lazer, vivenciá-lo de forma lúdica e gratuita nos espaços públicos que deveriam ser disponibilizados pelo Poder Público na cidade poderia ser uma opção. Assim, a existência de playgrounds nos bairros pode ampliar as possibilidades de lazer infantil, principalmente das crianças menores que residem em bairros de renda muito baixa ou baixa, além de se tornarem mais uma área de lazer comunitário, que favorecem a convivência e a interação social das crianças e de suas famílias, estreitando laços de sociabilidade. Nesse sentido, uma melhor oferta e distribuição desse tipo de equipamento pode transformar a qualidade de vida do lazer infantil e familiar em muitas regiões da cidade.

Da mesma forma, os equipamentos públicos como as pistas de skate são fundamentais para a prática do lazer por jovens. Vivência diretamente associada a um estilo de vida urbano e das diferentes "tribos" presentes nas grandes cidades, é cada vez mais comum ver pela cidade de Montes Claros jovens reunidos para essa prática, o que também confirma a influência do "urbano", não somente nas taxas de crescimento da população, mas também nos modos de vida da população.

A existência de duas pistas de skate, uma na Praça do bairro Maracanã e outra na Praça do bairro Todos os Santos, como ponto de encontro para jovens dessas e de outras regiões da cidade, é um indicativo de que a construção desse tipo de equipamento pode também ser uma demanda dos jovens de outros bairros, daí a importância de se ouvir a população do bairro antes de se efetivar qualquer projeto de reforma de praça ou construção de novas praças e equipamentos.

Também nesse Mapa, evidencia-se que outro equipamento escasso e concentrado nas regiões com renda mais alta são as pistas de caminhada. A prática da caminhada tem crescido consideravelmente em várias regiões da cidade. Cada vez mais disseminada nos meios de comunicação e pela medicina preventiva por sua direta vinculação a um estilo de vida saudável, que contribui para o bem-estar e para evitar uma série de doenças, esse tipo de atividade física tem sido indicada para diferentes faixas etárias, principalmente para adultos e idosos de ambos os sexos, se tornando uma das práticas de lazer ativo mais vivenciadas pela população.

$\mathrm{Na}$ época de realização da pesquisa, foram identificadas três "pistas" públicas de caminhada e corrida. A primeira pista identificada é a "Avenida do Cooper", na região Sudoeste da cidade, que vai da Praça dos Jatobás até o Parque Municipal Milton Prates. Na divisa com as regiões do Major Prates e Ibituruna, a Av. Mestra Fininha, ou "Avenida do Cooper", é um espaço de referência para prática da caminhada ou da corrida na cidade, mesmo com o passeio desnivelado em alguns trechos e grande fluxo de automóveis em determinados horários. 
Os outros dois pontos que foram considerados como "pistas" de caminhada estão localizados em duas praças. O formato da Praça do São José favorece a existência da pista à sua volta, pois ela ocupa cerca de quatro quarteirões. Essa pista também é um espaço de referência para prática da caminhada da população do bairro e da região. A outra pista identificada está localizada na Praça do Todos os Santos e, embora ainda de pequena dimensão, também contorna toda a praça, sendo utilizada pela população local.

Como forma de suprir essa carência, o que se verifica é uma intensa apropriação da população da calçada de avenidas largas que cortam a cidade, além do passeio de algumas praças de dimensões maiores. Com o objetivo de sinalizar essa tendência, foram identificados no Mapa da figura 7, além das três "pistas" consideradas, outros locais de caminhada disseminados por diversas regiões da cidade. Ressalta-se que a identificação desses outros locais de caminhada não tem o objetivo de esgotar todos os espaços em que essa prática ocorre, uma vez que esse é um processo muito dinâmico e cada vez mais disseminado por diferentes locais.

O fenômeno da prática da caminhada/corrida como vivência de lazer é uma das práticas de lazer mais democráticas, estando presente em várias regiões, mesmo naquelas com indicadores socioeconômicos muito contrastantes. Porém, o que se evidencia é uma diferença significativa na infraestrutura dos locais e condições em que a população realiza essa prática, uma vez que nas regiões com renda média e alta, houve um maior investimento do Poder Público Municipal nesse aspecto.

Diretamente associada à prática da caminhada ou da corrida como vivência físico-esportiva do lazer, as barras de ginástica e/ou alongamento existentes na cidade podem ser utilizadas como equipamento público de lazer complementar a essa atividade ou para prática de exercícios físicos específicos. Depois das quadras poliesportivas e campos de futebol, as barras de ginástica são os equipamentos mais numerosos, embora também seja evidenciada uma maior concentração desses equipamentos na região sudoeste da cidade.

No Mapa da figura 7, esses equipamentos foram identificados a partir de duas classificações: barras de ginástica em amarelo são aquelas formadas por um conjunto de no mínimo três tipos diferentes, dentre eles barras paralelas, para flexão, para alongamento e banco de abdominal, compondo um total de nove conjuntos de equipamentos que foram contabilizados para cálculo dos indicadores; barras de ginástica em vermelho (insuficientes), são formadas por apenas um tipo de barra ou estão em condições muito precárias. Apesar de mapeadas, não foram contabilizadas.

Sete conjuntos de barras estão localizados em praças no interior dos bairros, construídos seguindo, geralmente, o mesmo padrão, com exceção da Praça da Vila Oliveira e da Praça São Vicente (Santos Reis), que possuem equipamentos mais simples. Os outros três conjuntos estão localizados próximos a locais de caminhada muito frequentados.

\section{Figura 7: Mapa de Distribuição de outros Equipamentos de Lazer e Locais de caminhada}

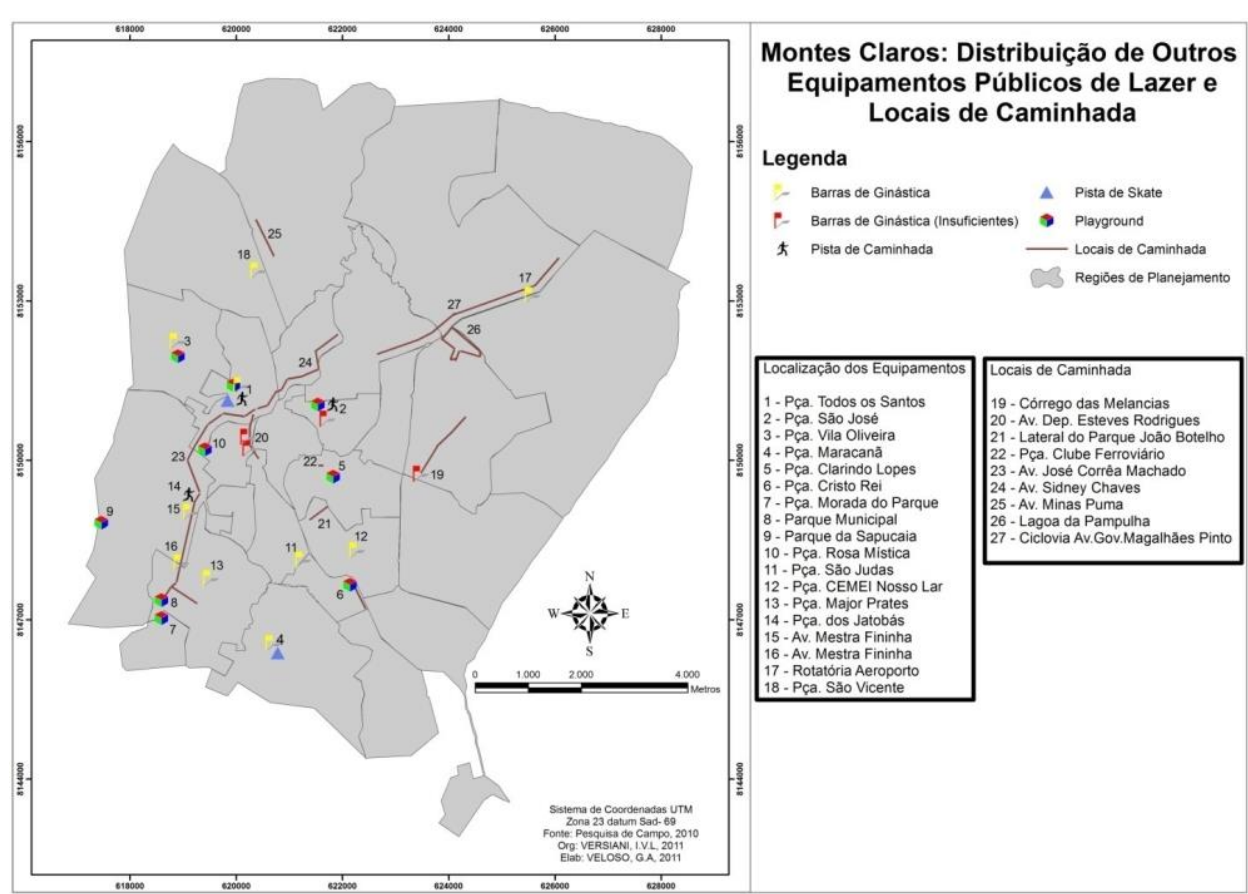

Fonte: Arquivo da autora. 
Fator de Desigualdade entre as Regiões e Fator de Diversidade de Equipamentos

Com relação ao fator de desigualdade entre as regiões, em função da existência de algumas que não possuem equipamentos públicos e/ou possuem, porém com acessibilidade restrita, o maior fator de desigualdade será justamente a porcentagem referente à região de maior concentração de equipamentos, ou seja, a da região do Major Prates. Assim, as regiões que apresentam o maior fator de desigualdade são: Santo Inácio (10); Santo Expedito (10) e Centro (10), seguidas pelas regiões que apresentam apenas um equipamento: Distrito Industrial (8); Independência (8); Vila Guilhermina (8). Logo depois, o índice cai pela metade, referente às regiões do Village do Lago (4); Alto da Boa Vista (4); Renascença (4); Santa Rita (4) e Edgar Pereira (4), que possuem dois equipamentos. A partir daí, o índice de desigualdade tende a se aproximar do 1 , valor de referência, variando de 2,7 a 1 - dependendo da porcentagem de equipamentos da região sobre o total da cidade, nas quinze regiões restantes.

Assim, percebe-se que ofator de desigualdade entre as regiões, para mais da metade delas é relativamente baixo, excetuando-se as seis regiões sem equipamento ou com apenas um equipamento, e as cinco subsequentes, que possuem apenas dois equipamentos. Apesar da influência de outras variáveis, esse dado poderia ser visto com otimismo, uma vez que não há uma discrepância muito acentuada para mais da metade delas no que diz respeito ao número total de equipamentos entre as regiões. Porém, é importante ressaltar que a média da cidade também é baixa, de três equipamentos por região, então essa baixa desigualdade reflete o baixo número de equipamentos na maioria delas.

A partir da apresentação desses três Mapas Temáticos, o que se pode perceber com relação específica ao fator de diversidade de equipamentos é que as regiões que têm uma maior diversidade são as que possuem seus equipamentos localizados em áreas institucionais implantadas que, de fato, podem ser chamadas de áreas de lazer, com praças dotadas de infraestrutura como iluminação, jardins, bancos, mesas e de pelo menos três equipamentos específicos. No outro extremo, há praças que somente têm a quadra, e há áreas institucionais apenas com a quadra e nada no entorno. A região com maior número de equipamentos, a do Major Prates, é também a que apresenta o maior grau de diversidade identificado na cidade (6), junto com a região do Maracanã (6), o que evidencia o potencial desse modelo para melhoria da qualidade de vida a ser disseminado por mais bairros de todas as regiões.

Outra tendência identificada é que se diminui a diversidade de equipamentos ao mesmo tempo em que se diminui a renda média da região, principalmente no que se refere à presença de playgrounds e pistas de caminhada. Excluindo-se aquelas regiões em que não há equipamentos, o fator de diversidade de equipamentos das regiões com renda baixa da cidade está restrito, em sua maioria, à existência de dois equipamentos: a quadra poliesportiva e o campo de futebol, ou somente um desses.

Conforme destacado, o número de equipamentos públicos de lazer, o fator de desigualdade, o fator de diversidade e a distribuição populacional irão influenciar a qualidade de vida dessas regiões no que se refere às vivências físico-esportivas, sobretudo das regiões com população de renda baixa e muito baixa. Com o objetivo de sintetizar essa discussão na dimensão intraurbana de Montes Claros, propõe-se como indicador o Índice de Qualidade de Vida de Lazer (IQV Lazer) aplicado a cada uma das regiões de planejamento, evidenciando-se as análises que podem ser feitas a partir do cruzamento desse indicador com os outros indicadores levantados.

\section{Índice de Qualidade de Vida Urbana para o Lazer (IQV Lazer)}

O cálculo do IQV Lazer para as Regiões de Planejamento foi realizado a partir do número total de equipamentos da região dividido pela sua população, por 1000 habitantes. Também foi realizado o cálculo do IQV Lazer para a cidade, a fim de se estabelecer uma classificação e comparação com base na média encontrada. Nota-se que a média para a cidade foi de 0,282 equipamentos para cada 1000 habitantes. Esse dado foi calculado com base nos dados populacionais do IBGE (2000) e será utilizado como referência, uma vez que os dados populacionais das regiões também são relativos ao Censo 2000.

A partir da média da cidade, os índices foram agrupados em quatro faixas de classificação: baixa/pior (variação de 0 a 0,100 ); abaixo da média (de 0,100 a 0,282$)$; acima da média $(0,282$ a 0,900$)$ e alta/melhor (acima de 0,900), conforme evidencia o Mapa da figura 8. A análise do IQV Lazer possibilita dimensionar o impacto do total de habitantes de uma determinada região correlacionado com o número de equipamentos, identificando-se, assim, áreas prioritárias para investimento. 
Figura 8: Mapa Síntese do IQV Lazer para Montes Claros

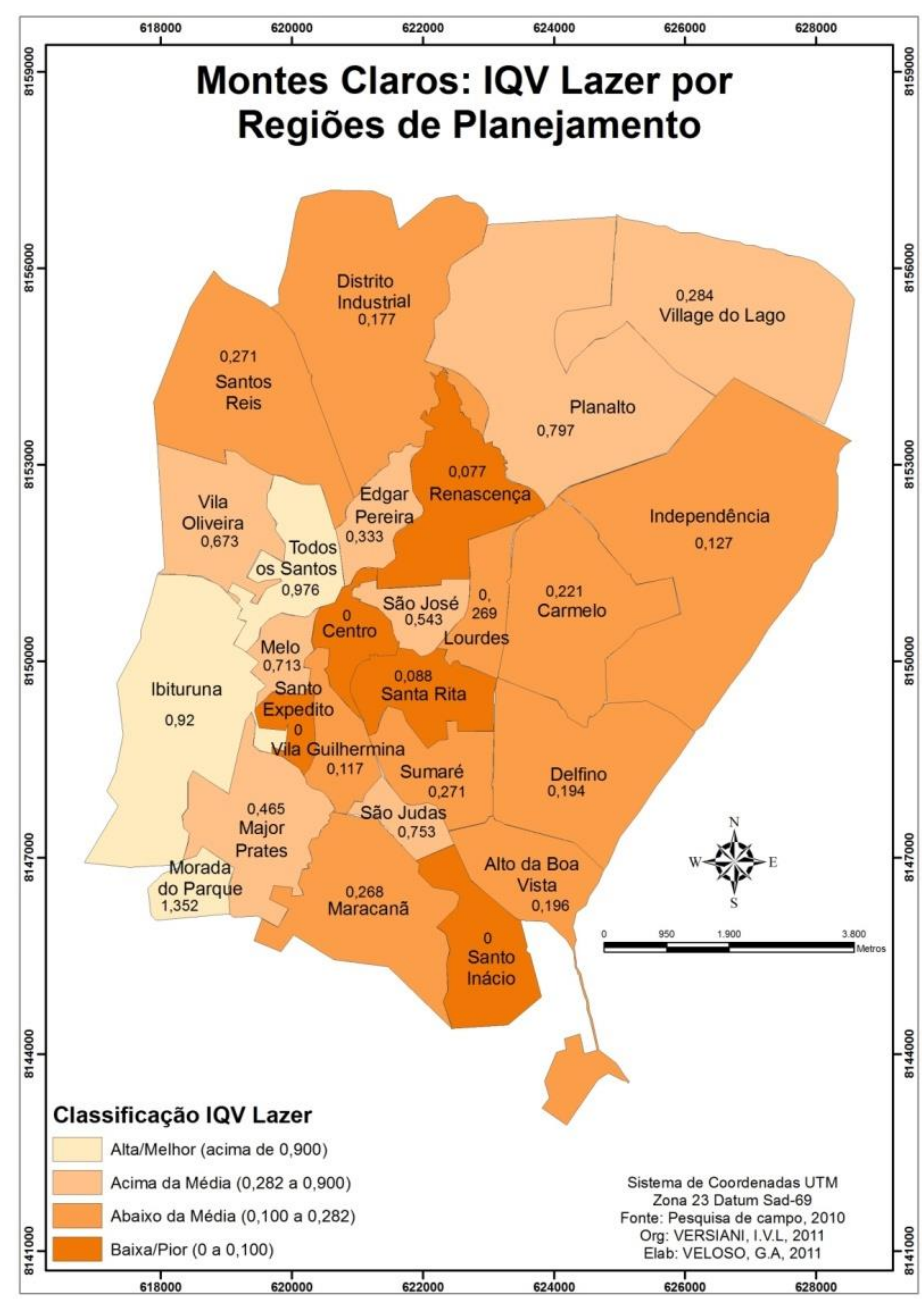

Fonte: Arquivo da autora.

$\mathrm{Na}$ análise do IQV Lazer, percebeu-se que as regiões de menor renda apresentam um número de equipamentos insuficientes para atender às demandas da população, apesar do número relativamente mais alto de equipamentos identificado nas regiões de renda baixa, que concentra quase $50 \%$ do total da cidade, porém tem sérias restrições quanto ao tipo de equipamento (na grande maioria são campos de várzea e quadras públicas com pouca infraestrutura). Além disso, a maioria dessas regiões está localizada na periferia da cidade, apresentando altas concentrações populacionais com renda baixa, o que compromete a relação da oferta com a demanda, uma vez que já são áreas carentes de alguns serviços e equipamentos públicos. Assim, o IQV Lazer da maioria dessas regiões acompanha os baixos indicadores socioeconômicos que conformam as condições de vida da população residente.

No outro extremo, regiões com renda média e alta, com exceção daquelas regiões que não possuem equipamentos ou possuem apenas um, apresentam IQV Lazer bem superior ao da média da cidade, além de serem regiões dotadas de boa infraestrutura e serviços públicos, com equipamentos diversificados e em bom estado de conservação. Além disso, o alto valor do solo urbano e a dimensão territorial menor influenciam o número de população residente, fazendo com que a maioria dessas regiões não apresente grandes concentrações populacionais.

Assim, o IQV Lazer apresenta-se como um indicador sintético da relação entre a distribuição de equipamentos públicos de lazer e a qualidade de vida urbana, em que as disparidades na dimensão intraurbana do município ficam evidentes, sobretudo quando correlacionado ao fator populacional e renda das regiões, podendo contribuir de maneira mais efetiva para o direcionamento de políticas públicas específicas, para um maior conhecimento e levantamento de informações tanto para o setor público, quanto para a população, potencializando 
reivindicações, pressões e ações na luta urbana cotidiana.

\section{DISCUSSÃO}

De acordo com Jacobs (2000, p.103), a transformação de equipamentos públicos de lazer em vazios urbanos desvitalizados, destruídos pela decadência, sem uso e desprezados pode ser retratada por sua impopularidade, o que preocupa, não só pelo desperdício e pelas oportunidades perdidas, mas também pelos efeitos negativos constantes (espalham riscos pela vizinhança; as ruas que os margeiam ganham fama de perigosas e são evitadas; o pouco uso transforma seus equipamentos em alvos de vandalismo).

$\mathrm{Na}$ pesquisa de campo, percebeu-se que os equipamentos localizados em praças que centralizam os serviços públicos oferecidos à comunidade, como Postos de Saúde, Centros de Assistência Social e Unidades da Polícia Militar, tendem a ser mais bem conservados, assim como aquelas praças em que há um envolvimento direto da Associação de Bairro ou de moradores da própria comunidade na preocupação com a conservação, melhorias e promoção de escolinhas de esportes e atividades comunitárias diversas nesses espaços.

Assim, verifica-se que a elaboração de diagnósticos de necessidades no campo do lazer, segundo Müller (2002), é um dos instrumentos que iniciam ações de planejamento e concepção de políticas públicas setoriais de esporte e lazer, contemplando indicadores sobre dados que podem ser históricos, político-administrativos, demográficos, de perfil psicográfico e de mapeamento de recursos.

A formulação de indicadores urbanos que avaliam a oferta disponível para a população, enfatizando a acessibilidade, possibilita ao poder público identificar "prioridades setoriais e também espaciais, para que suas políticas, programas e investimentos resultem em melhoria da qualidade de vida que a cidade oferece a seus moradores"; embora esbarre na dificuldade de lidar nas grandes cidades, e também, mais recentemente nas cidades médias, "com as profundas diferenças em seu interior, nos mais diversos aspectos" (NAHAS, 2008, p.96).

Nessa situação, torna-se indispensável a construção de indicadores georreferenciados no espaço intraurbano, permitindo também ao gestor público local a identificação de prioridades espaciais para certos investimentos, especialmente localização de equipamentos sociais que promovam um acesso equitativo a serviços e bens, promovendo a inclusão e a equidade" (NAHAS, 2008, p.96).

A presença de questões referentes ao lazer no planejamento urbano e o compartilhamento de experiências de investigação são importantes para o aprimoramento de indicadores, contribuindo para sua legitimação no debate em torno da qualidade de vida nas cidades e no direcionamento de ações específicas para suas políticas setoriais articuladas com as políticas urbanas, fundamentais em um contexto tão desigual de acesso a suas vivências.

Para Cruz (2001, p. 109), o espaço pode ser entendido como o centro das possibilidades de intervenção das prefeituras, principalmente quanto ao combate à especulação imobiliária, que favorece o uso do solo urbano para o enriquecimento de alguns e não o seu uso pela maioria. Na prática, segundo o autor, o que mais pode ser feito com relação aos espaços de lazer estaria diretamente relacionado à ampliação da rede de equipamentos, bem como a conservação adequada dos equipamentos e espaços públicos já existentes; à busca da democratização da discussão quanto à ocupação do solo urbano; à criação de leis para determinar o cumprimento de normas que garantam a existência de espaços adequados ao bem-viver nas diversas apropriações do solo urbano; à utilização das escolas municipais como centro de cultura e espaço para o lazer e, também, à discussão prévia entre técnicos e comunidade na instalação de equipamentos de lazer.

É necessário ressaltar que só a existência de um maior número ou uma maior diversidade de equipamentos não garante, necessariamente, a melhoria da qualidade de vida urbana de uma população no campo do lazer.

Nesse sentido, as políticas públicas de esporte e lazer também têm um papel importante para fomentar experiências e atividades que aproximem seus diversos conteúdos ao cotidiano dos moradores de cada bairro, no sentido de desenvolver uma “educação para e pelo lazer" (Marcellino, 2006), além de promover uma maior participação da própria população no cuidado e conservação desses espaços e equipamentos na direção de uma gestão compartilhada.

Ao aprofundar o modelo da gestão pública referente ao espaço de lazer e esporte na cidade, Rechia (2007, p. 249) identifica que:

O modelo de planejamento e gestão dos espaços destinados ao lazer, esporte, e cultura e as diversas possibilidades de intervenção nesses 
ambientes não é algo que possa ser tomado independente de um contexto maior de discussão sobre planejamento, a gestão e a dinâmica urbana de uma cidade. Portanto, um enfoque é fundamental para essa análise: tratase de visualizar a forma pela qual a evolução do tratamento da questão urbana vem se desenvolvendo, buscando inserir a discussão sobre o modelo das políticas públicas de lazer e esportes nesse contexto, no que se refere tanto ao planejamento dos espaços, quanto aos programas de intervenção.

Assim, priorizando-se a interação com diferentes aspectos que influenciam o cotidiano urbano, a infraestrutura de equipamentos e espaços, bem como o respeito às necessidades da população, a política de lazer traz uma nova forma de pensar a cidade em interface com seus espaços públicos, o que pode ser potencializado a partir da construção de indicadores de qualidade de vida urbana para seu constante monitoramento, divulgação e auxílio no direcionamento de ações para o planejamento urbano nesse campo.

Aprofundar o conhecimento da realidade do lazer nas cidades é fundamental para o seu desenvolvimento enquanto área da qualidade de vida e, conforme evidenciado, ao expor as desigualdades intraurbanas como no caso de Montes Claros, o levantamento desses indicadores torna-se uma ferramenta valiosa para o direcionamento de políticas públicas específicas e para ações integradas de planejamento urbano, podendo contribuir para novas possibilidades de pesquisas e ações nessa direção.

No caso da cidade de Montes Claros, a sistematização de informações que envolvem o lazer em interface com a qualidade de vida urbana, segundo alguns dos critérios levantados, pode contribuir para o processo de planejamento, elaboração, distribuição e implantação de Políticas Públicas de Esporte e Lazer relacionadas não só à estrutura física, mas também, aos programas e ações que buscam promover uma maior ocupação e apropriação desses equipamentos e espaços pela população.

Além da reforma de algumas quadras e praças, evidenciadas pelo levantamento das demandas do Orçamento Participativo, a partir da pesquisa de campo, ainda podem ser identificadas a necessidade de construção de novas quadras e áreas de lazer diversificadas em bairros que não possuem equipamentos públicos de lazer, de reforma e criação de novos campos de futebol, de ampliação e melhoria da oferta de playgrounds públicos, de se viabilizar a cobertura de outras quadras poliesportivas na cidade e de se implantar ou melhorar a iluminação para muitas delas, entre outras ações.

Assim, o conjunto de indicadores propostos podem ser considerados importantes instrumentos para auxiliar o Poder Público Municipal no direcionamento de investimentos, equipamentos e implantação de novos núcleos ou programas de Políticas Públicas, beneficiando, diretamente, aquelas regiões em que população se encontra mais exposta aos riscos sociais e carências de todos os tipos, contribuindo para uma maior democratização das vivências de lazer nas diferentes regiões da cidade.

Nessa perspectiva, para que essas ações se materializem, a Secretaria Municipal de Juventude, Esporte e Lazer não pode trabalhar de maneira isolada e nem tampouco fora das principais discussões no processo de planejamento urbano, uma vez que, através de suas competências, a mesma deve responder tanto pelo planejamento quanto pela implementação e manutenção dos espaços para atividades esportivas, recreativas e de lazer na cidade, bem como pela execução e coordenação de programas específicos que utilizem esses espaços e promovam sua maior apropriação pela população.

A necessidade dessa interação é evidente, embora dificuldades se coloquem no seu processo, principalmente quando se destaca a discussão de que o direito ao lazer está inserido em uma "hierarquia de necessidades" (MARCELLINO, 2006), que prejudica sua legitimação no debate político mais amplo. Tal constatação não é diferente também na realidade de Administração Pública de Montes Claros, cidade com tantas outras carências, nos mais diversos campos como na saúde, segurança pública, educação, infraestrutura urbana, habitação - que influenciam a qualidade de vida da população.

Daí a importância de se aplicar indicadores de qualidade de vida urbana para levantar informações e identificar desigualdades intraurbanas, auxiliando o Poder Público no direcionamento de políticas urbanas em interface com outras políticas públicas.

A busca por informações e a elaboração de diagnósticos acerca da realidade que compõe esses campos podem subsidiar e direcionar ações para uma outra forma de planejamento urbano que, de fato, amplie a qualidade de vida urbana de toda a população.

\section{CONSIDERAÇÕES FINAIS}

A associação do planejamento urbano à temática da qualidade de vida, tão presente hoje em dia nos mais variados campos, suscita mudanças de percepções, pensamentos e valores, tanto para o sentido e significado de ações, quanto para deliberações dos gestores. Está, também, ligada a 
uma nova visão de mundo e de cidade, que prioriza a dimensão coletiva e os interesses sociais, e que, no âmbito do espaço, busca ampliar as relações que o sujeito estabelece com o lugar onde vive.

O levantamento de informações relacionadas aos espaços e equipamentos públicos existentes para a vivência do lazer em uma cidade pode ser fundamental para um melhor direcionamento de ações de planejamento urbano e de políticas públicas de esporte e lazer, contribuindo para a melhoria da qualidade de vida urbana, principalmente para a população que se encontra distante do acesso aos equipamentos e espaços públicos existentes ou que não possuem condições materiais suficientes para consumi-lo nos moldes de mercadoria, forma majoritária com que o mesmo vem sendo ofertado na maioria das cidades.

Nesse contexto, pretendeu-se inserir essa discussão na cidade de Montes Claros, tomando como base a aplicação de alguns indicadores relacionados à distribuição de equipamentos públicos de lazer para vivência físico-esportiva, com o objetivo de melhor compreender alguns aspectos que podem influenciar a qualidade de vida urbana em interface com o campo do lazer nessa cidade.

Apesar da impossibilidade de se estabelecer um parâmetro comparativo dos equipamentos de Montes Claros com outras cidades médias ou mesmo com grandes cidades brasileiras, as diferenças se tornam claras quando se procede a comparações entre as diferentes regiões que configuram o mosaico socioespacial da cidade, principalmente quando se insere a renda média da região e a distribuição populacional correlacionada à distribuição dos equipamentos.

Através desses dados, foi possível conhecer melhor a infraestrutura dos equipamentos públicos de lazer para vivência físico-esportiva em Montes Claros; porém, constatou-se que o campo do lazer acompanha e, em algumas situações, amplia contradições socioespaciais existentes na cidade, influenciado por uma desigual distribuição, conservação e diversidade de seus equipamentos entre as regiões, apesar das diretrizes existentes em diferentes legislações urbanísticas do município que ensejam outro caminho a ser seguido.

Entende-se, assim, que o planejamento urbano de uma cidade não é feito somente das diretrizes existentes em diversas legislações, mas, sobretudo, da articulação entre normas, regulamentos, instrumentos e, principalmente, ações, que requerem "vontade política" - entendida como uma posição firme do Poder Público Municipal na garantia dos interesses públicos e sociais, em detrimento de interesses políticos e econômicos privilegiados, respeitando-se a promoção das funções sociais da propriedade e da cidade - somada a um conhecimento específico dos problemas, necessidades e demandas da cidade e de sua população para que, de fato, o mesmo possa interferir na realidade do desenvolvimento urbano e promover uma maior justiça social e qualidade de vida para seus habitantes.

A aplicação desses indicadores de qualidade de vida urbana ao campo do lazer retratado busca evidenciar algumas das potencialidades que essa forma de sistematização de informações pode ensejar visando reduzir desigualdades, democratizar o lazer e aumentar a qualidade de vida urbana da população em todas as regiões de uma cidade, além de poder estabelecer relações e cruzamentos de informações com outros campos essenciais a esse tema, ampliando possibilidades de estudos futuros e contribuindo para uma maior legitimação do lazer como um direito social no meio urbano.

\section{REFERÊNCIAS}

Brasil. (2001). Congresso Nacional. Lei n. 10.257 de 10 de julho de 2001 (Estatuto da Cidade). Disponível

em: <http//www.planalto.gov.br/CCIVIL/LEIS_2001/L1 0257.htm> Acesso em: 10 maio 2008.

Belo Horizonte. (2006). Texto: Indicadores e resultados do IQVU 2006 - Nova Metodologia. Disponível em: < http://portalpbh.pbh.gov.br/pbh/ >. Último acesso em: Janeiro, 2010.

Bogotá Como Vamos. (2010). Colômbia. Disponível em: <http://www.bogotacomovamos.org >. Acesso em 15 jan. 2010.

Câmara, G. \& Davis, C. (2001); Introdução. In Câmara, G.; Davis, C.; Monteiro, A. Geoprocessamento: Teoria e Aplicações. Disponível: <htttp:// ww.dpi.inpe.br/gilberto/livro> . Acesso em: Nov., 2010.

Castells, M. (2006). A questão urbana. Tradução de Arlene Caetano. Rio de Janeiro: Paz e Terra.

Cruz, M. (2001). A experiência da frente popular de Florianópolis. In: CRUZ, Manuel. Lazer e esporte: políticas públicas.2.ed. Campinas, SP: Autores Associados, 87-116. 
Damiani, A. (2009). Urbanização Crítica e Produção do Espaço. In: CIDADES: Revista Científica/ Grupo de Estudos Urbanos. Vol.6, n.10: 307-339.

Dumazedier, J. (1974). Sociologia Empírica do Lazer. São Paulo: Editora Perspectiva,. 244 p.

Global City Indicators. (2002). Indicadores Urbanos Globais: Uma Abordagem Integrada para a Mensuração e Monitoramento do Desempenho das Cidades. Disponível em: http://cityindicators.org>. Último acesso em: Out. 2010.

Gomes, C. (2006). Lazer e Cidade: reflexões. In: BRANDÃO, Carlos (Org.) As Cidades da Cidade, Belo Horizonte: Ed. UFMG, 171-184.

Gomes, C. (2014). Lazer: Necessidade Humana e Dimensão da Cultura. Revista Brasileira de Estudos do Lazer. Belo Horizonte, v.1, n.1, p.3-20, jan./abr. Disponível em: https://seer.ufmg.br/index.php/rbel/article/view/327. Acesso em: 14 jun. 2018.

Herculano, S. (1998). A qualidade de vida e seus indicadores. In: Revista Ambiente e Sociedade, Campinas, UNICAMP/NEPAM, Ano I, nº2, 01-24.

Instituto Brasileiro de Geografia e Estatística (IBGE). (2010). Censo Demográfico de 2010: primeiros resultados População e Domicílios recenseados.

Januzzi, P. (2009). Indicadores Sociais no Brasil: conceitos, fontes de dados e aplicações. 4. ed. Campinas, SP: Editora Alínea. 141 p.

Lefebvre, H. (2008). Espaço e Política. Belo Horizonte: Editora UFMG.

Leite, M. (2006). Geoprocessamento aplicado ao estudo do espaço urbano: o caso da cidade de Montes Claros. 106f. Dissertação (Mestrado em Geografia). Programa de Pós-Graduação em Geografia. Universidade Federal de Uberlândia. Uberlândia.

Leva, G. (2005). Indicadores de calidad de vida urbana: teoría y metodología. Argentina: Universidad Nacional de Quilmes.
Lojkine, J. (1997). O Estado capitalista e a questão urbana. 2. ed. São Paulo: Martins Fontes.

Marcellino, N. (2006). O lazer e os espaços na cidade. In YSAYAMA, Helder; LINHALES, Meily (Orgs.) Sobre lazer e política: maneiras de ver, maneiras de fazer. Belo Horizonte: Editora UFMG, 65-92.

Nahas, M. (2008). Qualidade de vida urbana em números. ComCiência (UNICAMP), v.96: 96.

Nahas, M. (2009). Indicadores Intra-Urbanos como instrumentos de gestão da qualidade de vida urbana em grandes cidades: uma discussão teórico-metodológica. In: Vitte, C.; (Orgs.) Qualidade de Vida, Planejamento $e$ Gestão Urbana: discussões teórico-metodológicas, Rio de Janeiro, Bertrand Brasil, 123-153.

Navarro, V. (2006). Trabalho, saúde e tempo livre sob os domínios do capital. In: Padilha, Walkíria (Org.). Dialética do Lazer. São Paulo: Cortez, 50-74.

Padilha, W. (2006). Introdução. In Padilha, W. (Org.). Dialética do Lazer. São Paulo: Cortez. 9-18

Porto (2018). Câmara Municipal. Sistema de Monitorização de Qualidade de Vida Urbana. Disponível em: < http://www.cmporto.pt/paginas_extra/smqvu- $>$. Acesso em: 15 jan. 2018.

Rechia, S. (2007). "Cidades Brasileiras: múltiplos desafios para as Políticas Públicas de Lazer e Esportes. In Melo, Victor et al. ; (Orgs.) A temática no âmbito das Ciências Humanas e Sociais _ anais do VIII Seminário Lazer em Debate. $1^{\text {a }}$ edição: Rio de Janeiro, 244-250.

Rede Nossa São Paulo (2016). Disponível em: $\langle$ http://www.nossasaopaulo.org.br/portal $>$. Acesso em: Out. 2016.

Santos, E. (2009). Avaliação de Espaços destinados ao lazer esportivo: notas sobre uma proposta metodológica. In ARQUIVOS EM MOVIMENTO - UFRJ. V. 5, N. 1, 135-152.

The Quality Of Life Project (2010). Nova Zelândia. Disponível em: <http://www.bigcities.govt.nz/index.htm> . Acesso em: 15 jan. 2010. 
II Versiani, I. et al (2019). A relação consumo e cidadania nas vivências de lazer nas cidades: em busca de uma maior democratização. RENEF, [S.1.], v. 9, n. 13, set. ISSN 2526-8007. Disponível em: http://www.renef.unimontes.br/index.php/renef/artic le/view/245. Acesso em: 03 dez. 2019.
Vitte, C. \& Keinert, T. (2009). Apresentação. In Vitte, C. \& Keinert, T (Orgs.) Qualidade de Vida, Planejamento e Gestão Urbana: discussões teóricometodológicas, Rio de Janeiro: Bertrand Brasil. 0911. 